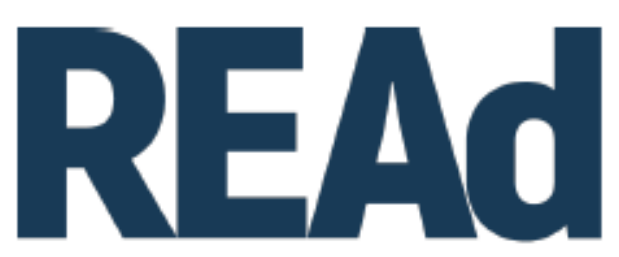

Revista Eletrônica de Administração

\title{
REPRESENTAÇÕES DO TRABALHO ESCRAVO NA CONTEMPORANEIDADE: DISPUTAS SEMÂNTICAS, MEMÓRIAS E SILENCIAMENTOS ${ }^{1}$
}

\author{
Georgiana Luna Batinga ${ }^{2}$ \\ Luiz Alex Silva Saraiva ${ }^{3}$ \\ Marcelo de Rezende Pinto ${ }^{4}$
}

\section{http://dx.doi.org/10.1590/1413-2311.286.100655}

\section{RESUMO}

Este ensaio foi elaborado com o objetivo de apresentar uma discussão sobre o trabalho escravo no contexto brasileiro e as disputas semânticas em torno da construção de um conceito que possa apreender suas representações na contemporaneidade. Para isso, apropriase de registros de nossa memória, apontando as continuidades históricas, os silenciamentos e dissimulações que atravessam a discussão, tentando aproximá-la do campo da Administração. Observa-se que o trabalho escravo sempre esteve presente na história da humanidade, sendo recorrente sua utilização por várias civilizações, seja pela força coercitiva, aquisição da mão de obra ou por outras formas e interesses. As reflexões apontam que, em detrimento das lutas travadas pela sua extinção até os dias atuais, pode-se afirmar que o trabalho escravo tem resistido e se reconfigurado no tempo e no espaço. O sistema de escravidão aparece e reaparece ao longo da história do trabalho, de maneira atemporal, assumindo novos contextos e formatos, da senzala à escravidão fabril, as oficinas de costura que integram a cadeia produtiva da indústria têxtil, negócios agropecuários, construção civil e outros setores da

\footnotetext{
${ }^{1}$ Recebido em 24/2/2020, aceito em 29/7/2020.

2 Universidade Federal de Mato Grosso do Sul - Escola de Administração, Campo Grande - MS, (Brasil); http://orcid.org/0000-0002-1807-9824; georgiana.luna@ufms.br.

${ }^{3}$ Universidade Federal de Minas Gerais - Centro de Pós-Graduação e Pesquisas em Administração, Belo Horizonte (Brasil); http://orcid.org/0000-0001-5307-9750; saraivalas@ gmail.com.

${ }^{4}$ Pontifícia Universidade Católica de Minas Gerais, Programa de Pós-Graduação em Administração, Belo Horizonte, MG (Brasil), http://orcid.org/0000-0002-3251-2460; marcrez@ pucminas.br.
} 
economia. Seja utilizando a mão de obra de nacionais ou imigrantes, o trabalho escravo é, sobretudo, fruto das ostensivas desigualdades sociais que devastam o mundo.

Palavras-chave: Trabalho Escravo. Memórias. Continuidades Históricas. Disputas Semânticas. Silêncios.

\section{REPRESENTATIONS OF SLAVE LABOR IN CONTEMPORARY TIMES: SEMANTIC DISPUTES, MEMORIES AND SILENCES}

This essay was designed with the objective of presenting a discussion on slave labor in the Brazilian context, as well as the semantic disputes surrounding the construction of a concept that can apprehend its representations in contemporary times. For that, it appropriates records from our memory, pointing out its historical continuities and the silences that go through the discussion, trying to bring it closer to the field of Administration. It is observed that slave labor has always been present in the history of mankind, with its use recurring by various civilizations, whether by coercive force, acquisition of labor or other forms and interests. To the detriment of the struggles waged by its extinction to the present day, it can be said that slave labor has resisted and been reconfigured in time and space. The slavery system appears and reappears throughout the history of work, in a timeless manner, taking on new contexts and formats, from slave quarters to factory slavery, the sewing workshops of luxury brands, agricultural business, civil construction and other sectors of the economy. Whether with the labor of nationals or immigrants, contemporary slave labor is, above all, the result of the ostensible social inequalities that devastate the world.

Keywords: Slave Labor. Memories. Historical Continuities. Semantic Disputes. Silence.

\section{REPRESENTACIONES DEL TRABAJO ESCLAVO EN LOS TIEMPOS CONTEMPORÁNEOS: DISPUTAS SEMÁNTICAS, RECUERDOS Y SILENCIOS}

Este ensayo fue diseñado con el objetivo de presentar una discusión sobre el trabajo esclavo en el contexto brasileño, así como las disputas semánticas que rodean la construcción de un concepto que puede aprehender sus representaciones en los tiempos contemporáneos. Para eso, se apropia de los registros de nuestra memoria, señalando sus continuidades históricas y (c) (1) (9) REAd | Porto Alegre - Vol. 26 - N. ${ }^{\circ} 2$ - Maio / Agosto 2020 - p. 330-351. 
los silencios que pasan por la discusión, tratando de acercarlo al campo de la Administración. Se observa que el trabajo esclavo siempre ha estado presente en la historia de la humanidad, con su uso recurrente por varias civilizaciones, ya sea por fuerza coercitiva, adquisición de trabajo u otras formas e intereses. En detrimento de las luchas libradas por su extinción hasta nuestros días, se puede decir que el trabajo esclavo ha resistido y se ha reconfigurado en el tiempo y espacio. El sistema de esclavitud aparece y reaparece a lo largo de la historia del trabajo, de manera atemporal, adoptando nuevos contextos y formatos, desde los cuartos de esclavos hasta la esclavitud en fábricas, los talleres de costura de marcas de lujo, negocios agrícolas, construcción civil y otros sectores de la economía. Ya sea con el trabajo de nacionales o inmigrantes, el trabajo esclavo contemporáneo es, sobre todo, el resultado de las aparentes desigualdades sociales que devastan el mundo.

Palabras clave: Trabajo Esclavo. Recuerdos. Continuidades Históricas. Disputas Semánticas. Silencios.

\section{INTRODUÇÃO}

O trabalho escravo é um fenômeno social antigo, extenso, complexo e circunscrito em um conjunto de situações extremas que pleiteiam uma abordagem multidisciplinar, com ações de enfrentamento constituídas a partir de múltiplos olhares. Longe de ser considerado um fenômeno recente ou disperso, o trabalho escravo tem resistido e se reconfigurado no tempo e no espaço, apresentando manifestações sutis e dissimuladas, mas igualmente perversas. Fruto de vulnerabilidades socioeconômicas, socioculturais e até geográficas, que sustentam práticas de escravidão até os dias atuais (BAPTISTA; BANDEIRA; SOUZA, 2018), não é simples reconhecer, admitir ou confirmar sua existência, pois as disputas semânticas travadas em torno de uma terminologia apropriada, assim como de uma conceituação vigente que possa incorporar uma definição, persistem e representam entraves aos processos, julgamentos e decisões legais em torno do tema.

A problemática em torno da semântica consiste em incorporar o significado e a interpretação desse significado de maneira isolada, desconectado das condições de produção dessa "verdade". Neste caso, estamos lidando diretamente com o eufemismo semântico, um recurso linguístico usado para suavizar e abrandar o significado original de um léxico que pressupõe ser agressivo, mantendo, dessa maneira, o distanciamento histórico do conjunto de memórias evocadas quando falamos em escravidão ou trabalho escravo. Dessa forma, parece 
ser mais fácil admitir as categorias 'trabalho forçado', 'jornada exaustiva', 'condições degradantes' ou mesmo o 'trabalho precário', a admitir a vigência da escravidão na contemporaneidade. Parte dessa discussão remete à negação de sua permanência até os dias atuais e aos questionamentos em torno do que possa configurá-la ou defini-la, em que se assemelha ou se diferencia da escravidão moderna. Assumir a escravização representa um desafio, pois remete à própria estimativa temporal, por ser um fenômeno de duração indeterminada. A questão da temporalidade e de sua estimativa está vinculada à identificação do crime e esse desafio também é agravado pelo fato de que as vítimas da escravidão se encontram frequentemente isoladas e amedrontadas (DATTA; BALES, 2013).

A complexidade, ambivalência e ambiguidade que acompanham o tema contribuem para que ele ocupe espaço nas agendas interinstitucionais, que contemplam interesses do Estado, agências humanitárias, sociedade e academia, que têm produzido discussões extensas a esse respeito, sobretudo no Direito, na perspectiva do direito do trabalho, no âmbito das leis que regem as relações de trabalho e direitos humanos, na História, com estudos voltados a historiografia do tema, na Sociologia, com as temáticas sociais e da sociologia do trabalho, nos aspectos sociais e humanistas do Serviço Social, e em menor expressão em outras áreas, como a Geografia, Comunicação, Jornalismo e outros. Nesse ponto, não se pode negar a estreita relação que o tema em questão possui com o ambiente da organização e, consequentemente da Administração. É uma discussão que perpassa decisões estratégicas de gestão, relações de trabalho diretas e terceirizadas, gestão da cadeia produtiva, responsabilidade social corporativa, transações mercantis, entre outros, questões inerentes ao escopo da Gestão.

Para além disso, há todo um espectro de possibilidades não comprometidas propriamente com os resultados e interesses organizacionais, mas com o humano, do ponto de vista das relações psicossociais, que também considera a importância de sua escolha, particularmente no contexto do Brasil, considerado o último país da América a abolir a escravidão. Considerado um tema preterido nas Ciências Sociais e via de regra inexplorado na Administração, entendemos que precisamos retomar sua discussão no escopo da Administração, que apresenta poucos registros a esse respeito (BALES, 2004; COOKE, 2003; CRANE, 2013). O que é lamentável, pois "a pesquisa em gestão assume um lugar relevante na explicação da persistência da escravidão, principalmente em termos das regras, normas e práticas que estruturam e conduzem a questão" (CRANE, 2013, p. 49). Isso se intensifica quando observamos o contexto brasileiro, pois é importante ressaltar os aspectos culturais e (c) (1) $\left(\right.$ REAd | Porto Alegre - Vol. 26 - N. ${ }^{\circ} 2$ - Maio / Agosto 2020 - p. 330-351. 
sociais que legitimam essas práticas nas organizações, diante dos desafios de uma corrupção estruturada que assola nosso país (MASCARENHAS; DIAS; BAPTISTA, 2015).

Identificamos neste ponto, o que chamamos de um silenciamento que tem muito a nos dizer, pois o não-dito assume em vários contextos, o papel de mediador entre as relações sociais e a linguagem (ORLANDI, 2007). Desse modo, entendemos que ele reflete, em certa medida, o esvaziamento nas narrativas históricas do país, da mesma forma que a retomada de discussões acerca do tema coincidem com o aumento de sua visibilidade que tem repercutido na mídia nacional. Semelhantemente, esse silenciamento histórico também pode ser observado no âmbito dos estudos de gestão norte-americanos, por exemplo, quando se busca tais publicações em períodos antigos, pré-modernos e contemporâneos, nos quais são se encontram relatos sobre a escravidão norte-americana. Não há apenas uma ausência, mas também uma abrangente negação do trabalho escravo nos relatos históricos da Administração, assim como nos estudos e publicações sobre gestão e liderança (HAYEK et al., 2010).

A maioria dos pesquisadores mais ortodoxos admitem a escravidão, mas a "localizam fora do ambiente da gestão moderna" (COOKE, 2003, p. 1899). Embora várias razões possam ser atribuídas a essa negação, há pouca dúvida de que a "lealdade" ao campo e o peso que se pode carregar ao admitir um capítulo tão obscuro da história sejam as motivações para se evitar o olhar questionador dentro da disciplina. Dessa forma, na tentativa de oferecer elementos que possam contribuir para o preenchimento desse espaço, delineamos aqui, "pensar o passado para ver e estabelecer diferenças, semelhanças ou igualdades" (GUARINELLO, 2006, p. 228). Refletindo acerca do trabalho escravo no contexto brasileiro, assim como as disputas semânticas em torno da construção de um conceito que possa apreender suas representações na contemporaneidade. Para isso, recorre-se a uma historiografia com o resgate de registros de nossa memória, apontando suas continuidades históricas e os silenciamentos que atravessam a discussão, tentando aproximá-la do campo da Administração.

Portanto, no intuito de oferecer uma fundamentação teórica pertinente a discussão que pretende ser abordada aqui, apresenta-se um breve resgate do contexto sócio-histórico do trabalho escravo no mundo e no Brasil, ainda na condição de colônia, quando instituído pela coroa portuguesa a partir do ano 1530, considerado uma atividade legal com o apoio do sistema jurídico e da Igreja, sendo extinto oficialmente por meio da Lei áurea em 1888. Em sequência, discute-se as representações e dissimulações do tema na contemporaneidade nos contextos rural e urbano, com formas que se configuram a partir do que herdamos do trabalho (c) (1) $\Theta$ REAd | Porto Alegre - Vol. 26 - N. ${ }^{\circ} 2$ - Maio / Agosto 2020 - p. 330-351. 
escravo moderno, associando-o às relações de trabalho constituídas posteriores à abolição, qual seja, a passagem da escravidão para o trabalho assalariado.

\section{UMA BREVE HISTORIOGRAFIA DO TRABALHO ESCRAVO}

Presente na história desde tempos remotos, não há registros históricos que possam afirmar com precisão o lugar, a data e as motivações primárias para a aparição dessa prática. "A historiografia trata a escravidão como se fosse um fenômeno quase universal, presente em diferentes graus de intensidade, em quase todas as sociedades humanas pré-capitalistas" (GUARINELLO, 2006, p. 229). A escravidão é considerada a primeira forma organizada de trabalho do mundo e pode ser definida como uma instituição histórica, um modo de produção, ou ainda uma prática social que carrega em si, o trabalho escravo executado pelo trabalhador escravo, ou simplesmente escravo. Possui como principal tipificação subjugar um ser humano a outro, com severidade e de tal maneira que não se limita ao seu corpo apenas, mas também de sua própria vontade, que é anulada e sujeita a autoridade de seu senhor (PINSKY, 2012; GUARINELLO, 2006; PEREIRA, 2008).

No mundo antigo várias civilizações, tais como babilônios, egípcios, assírios, hebreus, gregos e romanos utilizaram a mão de obra de trabalhadores escravos. Configura-se como um fenômeno histórico extenso e diverso, presente em todos os continentes, Ásia, na Europa, nas Américas e na África. Durante milênios, a humanidade conviveu com diferentes formas de trabalho compulsório, dentre elas, a exploração do trabalho escravo, que foi responsável pelo desenvolvimento econômico de várias civilizações, impérios, nações, cidades-estados, povos tribais e outros grupos. O trabalho escravo foi praticado por diversos povos durante toda a história, de modos diferentes e específicos, inúmeras civilizações dependeram do trabalho escravo para sua sobrevivência (PEDROSO, 2006; GUARINELLO, 2006; PEREIRA, 2008).

Foi utilizado para a execução de tarefas domésticas, rudimentares e atividades mais pesadas, conforme relatos dos hebreus, povo que se tornou cativo da nação egípcia, cuja servidão se deu na construção de templos, palácios e monumentos. Várias eram as formas de aquisição dessa mão de obra, desde a compra em leilões, comercializados em mercados públicos, até a captura de estrangeiros e prisioneiros de guerras, onde a pessoa apreendida se tornava res, ou seja, uma propriedade particular de outrem, sendo obrigada a trabalhar forçadamente, caso contrário poderia ser passível de punição corporal, "fato que representava 
uma marca de civilidade para a época, pois sociedades anteriores praticavam a antropofagia e a imolação de prisioneiros" (MARTINS, 2003, p. 34).

Não é possível tentar definir com precisão a escravidão no mundo antigo, o que se observam são tentativas de se construir uma narrativa histórica que possa representá-la. A imagem que construímos ancora-se em certa medida "na experiência da escravidão colonial nas Américas, particularmente as do sul dos Estados Unidos, do Caribe e do Brasil que, por sua vez, buscaram grande parte de seus fundamentos jurídicos no direito romano" (GUARINELLO, 2006, p. 229). Destacam-se também as civilizações babilônica e greco- romana que detinham uma considerável quantidade de escravos. "Por não considerar o trabalho uma ocupação de prestígio, apoiados no pensamento aristotélico de que "pensar requer ócio", a elite grega utilizava dos escravos" (PEREIRA, 2008, p. 2).

No decorrer da história, o trabalho escravo revela-se, em cada período histórico, com facetas e configurações distintas, baseadas em diversos fatores, no entanto, a característica mais marcante sempre foi a exploração extrema e a objetificação do ser humano, a serviço do outro (PEDROSO, 2006). É importante ressaltar que existem várias modalidades de escravidão na história da humanidade: “a escravidão ritual praticada pelos povos indígenas tupis brasileiros, a escravidão voluntária e temporária dos textos hebraicos, o escravo africano moderno, utilizado violentamente por um amplo sistema comercial, e outros", no entanto, a mais comum, e ao mesmo tempo mais extrema é a escravidão que utiliza o sujeito como "propriedade, e, na maioria das vezes um estrangeiro adquirido para ser uma coisa pertencendo a outro indivíduo, que seria senhor, não somente de seu trabalho, mas de seu próprio corpo" (GUARINELLO, 2006, p. 229).

O trabalhador escravo era um "objeto das mais variadas transações: venda, compra, empréstimo, doação, transmissão por herança, penhor, sequestro, embargo, depósito, arremate e adjudicação". Era, por definição jurídica e social, uma propriedade”. Segundo historiadores e juristas da época, o escravo "só se transformava em "pessoa" quando considerado um criminoso, pois assim poderia ser julgado e condenado como tal" (FLORENTINO; GOES, 1997, p. 30-31); é “o ato de tornar um ser humano uma propriedade de outrem. Este fundamento é tão inerente à escravização que pode ser observada nos diferentes lugares e tempos em que existiu” (COSTA, 2014, p. 320).

No Brasil não foi diferente, no início do processo de colonização a prática foi instituída pela coroa portuguesa a partir do ano 1530, considerado uma atividade legal, com o apoio do sistema jurídico e da Igreja, explorou e subjugou o índio e o negro africano. No (c) $(1) \Theta$ 
Brasil colônia, até meados do século XVI, prevalecia a exploração do trabalho escravo indígena. A partir desta data, registra-se a chegada dos primeiros escravos africanos trazidos para trabalharem nos engenhos brasileiros localizados na Zona da Mata pernambucana e Recôncavo Baiano. Há poucos registros sobre esse período e não há como se aferir a extensão do regime escravista desta época, mas é certo que não foram casos isolados, mas uma estrutura de trabalho legalizada e regulamentada pela Coroa portuguesa. Em relação aos custos inerentes à importação, obviamente transformaram o trabalho escravo africano bem mais caro que a exploração dos indígenas: "um escravo africano custava, na segunda metade do século XVI, cerca de três vezes mais que um escravo índio" (MARQUESE, 2006, p. 111).

A passagem da escravidão indígena para a africana, "ocorre após vários surtos de sarampo e varíola, que acabou matando um grande número de escravos índios, o que exigia reposição constante da força de trabalho nos engenhos", além disso, pressionados pelos jesuítas, a coroa portuguesa emite uma lei que proíbe, ainda que parcialmente, a exploração da mão de obra indígena nessas condições. "Ao mesmo tempo, os portugueses aprimoravam o funcionamento do tráfico negreiro transatlântico, sobretudo após a conquista definitiva de Angola em fins do século XVI" (MARQUESE, 2006, p. 111).

A herança escravagista é marcadamente evidente em nossa história, pois dentre todos os países do continente americano, o Brasil ocupou o primeiro lugar na condição de "maior importador de escravos das Américas". Uma consulta ao acervo digital da Biblioteca Nacional do Rio de Janeiro, encontramos registros históricos que estimam em "quase 10 milhões de negros foram levados para as Américas, entre os séculos XV e XIX”. Dentre esses, para o Brasil, "estima-se que teriam vindo cerca de 3.650.000,00, escravos africanos oriundos do Guiné, Sudão, Congo, Angola, Moçambique, entre outros, representantes de várias etnias, como os afantis, jejes, peuls, hauçás, nagôs ou iorubas e banto" (BIBLIOTECA NACIONAL DO RIO DE JANEIRO, 1988, p.9).

Esses escravos atuavam no país em várias atividades, no campo, nas atividades centrais que sustentavam a colônia, onde se dedicavam "ao cultivo da cana-de-açúcar, algodão, fumo, café e extração de metais preciosos; nos ofícios especializavam-se na construção, carpintaria, olaria, sapataria, ferraria, entre outros”. Os serviços domésticos eram reservados aqueles considerados mais "sociáveis", nos registros históricos denominados de "negros domésticos", cujas atribuições eram os "cuidados das atividades das casas grandes e das habitações urbanas e se dedicavam a carregar água, retirar o lixo, além de transportar fardos e os seus senhores em redes, cadeiras e palaquins". No período colonial, quase a (c) (1) $\left(\right.$ REAd | Porto Alegre - Vol. 26 - N. ${ }^{\circ} 2$ - Maio / Agosto 2020 - p. 330-351. 
totalidade das atividades eram desenvolvidas por meio da exploração do trabalho de escravos negros "nas minas e lavouras de exportação, [...], era comum o escravo trabalhar até 14 ou 16 horas, [...], em geral amontoavam-se em senzalas impróprias para a habitação e careciam de cuidados médicos” (BIBLIOTECA NACIONAL DO RIO DE JANEIRO, 1988, p. 10-11).

As condições de trabalho a que eram submetidos era de intensa exploração, sofrimento e violência, alimentavam-se e vestiam-se mal, ficavam expostos ao tempo, as condições de moradia (senzalas) eram impróprias e insalubres, constantemente sofriam com doenças endêmicas, como, tuberculose, tifo, malária, entre outras. A sujeição se dava também "na obediência e respeito às leis e dispositivos disciplinares, os senhores exigiam dos escravos fidelidade, humildade e aceitação dos valores brancos". Eram-lhes exigidos o aprendizado da língua portuguesa e "se convertiam a religião católica, ao chegarem ao Brasil, eram batizados, recebiam nomes cristãos, e sofriam perseguição pela prática dos cultos africanos" (BIBLIOTECA NACIONAL DO RIO DE JANEIRO, 1988, p. 10-11).

O retrato da escravidão em solo brasileiro é configurado principalmente de uma herança histórica advinda das "colônias caribenhas inglesas e francesas do século XVIII, adotada no Brasil, na primeira metade do século XVII", e começa a perder opulência nos próximos séculos que se seguem, passando a apoiar-se em uma "estreita articulação entre o tráfico transatlântico de escravos bastante volumoso e o número constante de alforrias". Para o autor, "nessa equação, era possível aumentar a intensidade do tráfico, com a introdução de grandes quantidades de trabalhadores africanos escravizados, sem colocar em risco a 'ordem social escravista"” (MARQUESE, 2006, p.109).

Não se pode precisar uma data sobre o início dos movimentos abolicionistas no Brasil, pois, no decorrer dos três séculos de escravidão institucionalizada, a sociedade sempre abrigou partidários e opositores. Entretanto, enquanto movimento social organizado, o abolicionismo se fortaleceu entre as décadas de 1860 e 1880. O processo da "Abolição da Escravatura no Brasil" foi conquistado com muita luta (PATROCÍNIO, 1882; NABUCO, 1883; BRUSANTIN; BARBOSA; CAMPOS, 2010).

Múltiplos interesses transitaram entre os "ideais de liberdade dos escravos e ganharam força com o apoio de abolicionistas e de alguns setores da classe dominante que, de forma progressiva, interferiram para que a emancipação dos negros fosse concretizada". A abolição não representava apenas um clamor pela justiça e pela igualdade, mas sobretudo por interesses econômicos, pois o escravo se tornara uma mão de obra cara e obsoleta. Dessa 
forma, pressionada a adotar uma posição a esse respeito, a Coroa portuguesa iniciou uma série de decisões que culminariam na abolição da escravidão no país (BRUSANTIN; BARBOSA; CAMPOS, 2010, p. 47).

No Brasil, a abolição da escravidão se dá por meio de um decreto, que finaliza o direito de propriedade de uma pessoa sobre outra, quando, no dia 13 de maio de 1888, a princesa Isabel sancionava a Lei Áurea. Há muitas críticas a esse respeito, na opinião de historiadores, a abolição da escravatura no Brasil, mesmo com a participação dos negros em movimentos, quilombos e outros foi "um negócio de brancos e para brancos". É certo que a lei Áurea libertou o trabalhador escravo da condição legal de propriedade de seu senhor, mas não o libertou da condição subalterna na sociedade, pois não houve reparação e indenização e nem lhes foi oferecida nenhuma condição para o exercício de sua liberdade, ficando à mercê da exploração assalariada de seu trabalho (FERNANDES, 1965; LARA, 1998). “Os negros, a despeito da liberdade jurídica obtida, foram duplamente espoliados: não receberam nenhuma indenização pelos quase 350 anos de escravidão e ainda viram abalar-se seu principal liame com a sociedade, ou seja, o trabalho" (FERNANDES, 1965, p. 49).

\section{REPRESENTAÇÕES DO TRABALHO ESCRAVO CONTEMPORÂNEO}

Nos anos que se seguiram, início do século XIX e XX, o trabalho assalariado, que ganhava espaço por ser mais eficiente e menos custoso, representava uma continuidade histórica do trabalho escravo, enraizado em nossa sociedade por mais de três séculos, e se traduzia na exploração do trabalho de nacionais e estrangeiros, no campo, com a presença de nordestinos trabalhando nas fazendas na região Norte do país (principalmente no período do ciclo da borracha) e imigrantes europeus na região Sudeste, (na cafeicultura). A resistência que se encontra no combate ao trabalho escravo, dentre outros motivos, se apoia principalmente em fatores econômicos, pois a escravidão contemporânea apresenta-se tão exitosa para o contexto organizacional quanto era no período colonial.

Para além das disputas semânticas e das configurações legais que definem o crime, no entanto, é certo que a escravidão contemporânea "é tão vantajosa para os empresários atuais, quanto era para os traficantes negreiros do Brasil Colônia e Império, pelo menos do ponto de vista financeiro e operacional", conforme estudo realizado pelo sociólogo americano Kevin Bales, considerado um dos maiores especialistas no tema, seus dados foram adaptados pelos 
autores do relatório da OIT para a realidade brasileira e pode ser conferido no Quadro 1 (BALES, 1993, apud OIT, 2006, p. 34).

Quadro 1 - Comparação entre a antiga e a nova escravidão

\begin{tabular}{|c|c|c|}
\hline Brasil & Antiga Escravidão & Nova Escravidão \\
\hline Propriedade legal & Permitida & Proibida \\
\hline $\begin{array}{l}\text { Custo de aquisição de mão-de- } \\
\text { obra }\end{array}$ & $\begin{array}{l}\text { Alto. A riqueza de uma pessoa } \\
\text { podia ser medida pela quantidade } \\
\text { de escravos. }\end{array}$ & $\begin{array}{l}\text { Muito baixo. Não há compra e, } \\
\text { muitas vezes, gasta-se apenas o } \\
\text { transporte. }\end{array}$ \\
\hline Lucros & $\begin{array}{l}\text { Baixos. Havia custos com a } \\
\text { manutenção dos escravos. }\end{array}$ & $\begin{array}{l}\text { Altos. Se alguém fica doente pode } \\
\text { ser mandado embora, sem nenhum } \\
\text { direito. }\end{array}$ \\
\hline Mão-de-obra & $\begin{array}{l}\text { Escassa. Dependia de tráfico } \\
\text { negreiro, prisão de índios ou } \\
\text { reprodução. }\end{array}$ & $\begin{array}{l}\text { Descartável. Um grande } \\
\text { contingente de trabalhadores } \\
\text { desempregados. Um homem foi } \\
\text { levado por um gato por R\$ } 150,00 \\
\text { em Eldorado dos Carajás, Sul do } \\
\text { Pará. }\end{array}$ \\
\hline Relacionamento & $\begin{array}{l}\text { Longo período. A vida inteira do } \\
\text { escravo e até de seus descendentes. }\end{array}$ & $\begin{array}{l}\text { Curto prazo. Terminado o serviço, } \\
\text { não é necessário mais prover o } \\
\text { sustento. }\end{array}$ \\
\hline Diferenças étnicas & Relevantes para a escravidão & $\begin{array}{l}\text { Pouco relevantes. Qualquer pessoa } \\
\text { pobre e miserável pode se tornar } \\
\text { um escravo, independentemente da } \\
\text { cor de sua pele ou de sua origem. }\end{array}$ \\
\hline Manutenção da ordem & $\begin{array}{l}\text { Ameaças, violência psicológica, } \\
\text { coerção física, } \\
\text { exemplares e até assassinatos. }\end{array}$ & $\begin{array}{l}\text { Ameaças, violência psicológica, } \\
\text { coerção física, } \\
\text { exemplares e até assassinatos. }\end{array}$ \\
\hline
\end{tabular}

Fonte: Organização Internacional do Trabalho - OIT (2006, p. 34). Trabalho escravo no Brasil do Século XXI. Brasília: OIT, p. 34.

Mais de um século se passou, e o Brasil e o mundo não podem afirmar que estão livres da escravidão. Segundo a Organização Internacional do Trabalho (OIT) (2017), estima-se que há cerca de 40 milhões de trabalhadores submetidos ao trabalho escravo na contemporaneidade. A mobilização internacional contra o trabalho escravo na contemporaneidade iniciou-se quatro décadas após a assinatura da Lei Áurea, por volta do ano 1930, quando a OIT aprovou, na cidade de Genebra, a Convenção 29 que pede a eliminação do trabalho forçado ou obrigatório. Vinte e sete anos depois, em 1957, a OIT assina a Convenção 105, que dispõe sobre o mesmo tema, mas amplia a discussão.

No Brasil, as primeiras denúncias a esse respeito iniciaram na década de 1970, com o apoio de movimentos sociais ligados à Igreja Católica e ao campo, mas somente vinte e cinco anos depois, em 1995, o país assume a presença de trabalho escravo em seu território. Tal reconhecimento ocorreu somente depois de pressões de organismos internacionais juntamente com um conjunto de denúncias, principalmente depois da repercussão internacional gerada 
pelo caso do ex-escravizado José Pereira Ferreira, que era mantido como escravo em uma fazenda no estado do Pará e conseguiu fugir com um companheiro. Durante a fuga, ele foi perseguido, baleado e seu corpo jogado em um riacho, mas conseguiu escapar ao fingir que estava morto, se deslocando a pé até a cidade mais próxima. Conhecido internacionalmente como o "caso Zé Pereira", foi considerado o primeiro relato sobre escravidão contemporânea em solo nacional "a ter repercussão mundial e atingir a toda comunidade internacional e assim trazer grandes repercussões hodiernamente" (RAMOS, 2016, p. 93).

Outro fato marcante na trajetória nacional de enfrentamento ao trabalho escravo, ocorreu no ano de 2003 quando o Congresso aprovou uma alteração no artigo 149 do Código Penal brasileiro, para aperfeiçoar a caracterização do crime. Desde então, de acordo com dados da Secretaria de Inspeção do Trabalho do extinto Ministério do Trabalho e Emprego, agora vinculado ao Ministério da Economia (SIT/ME), entre 1995 e 2018, cerca de 50 mil trabalhadores foram libertados em ações dos grupos móveis de fiscalização, integrados por auditores fiscais do trabalho, procuradores do trabalho e policiais federais. No conjunto de debates a esse respeito, está a terceirização, que recentemente passou a ser irrestrita (Lei 13.429/2017), prevista na legislação brasileira, na flexibilização das normas trabalhistas. A terceirização ancora-se na promessa de criação de novas vagas de emprego, mas desampara o trabalhador ao cercear seus direitos previstos em lei.

A terceirização, como o próprio nome diz, refere-se à transferência a terceiros da execução de serviços, assim como os custos trabalhistas da organização, e constitui-se como uma alternativa eficaz para a organização, pois proporciona agilidade, competitividade e liderança. No entanto, quando analisadas as desvantagens da terceirização, um dos tópicos mais apontados pelos estudiosos é a precarização dos postos de trabalho, o Tribunal Superior do Trabalho (TST) afirma que a terceirização afeta os terceirizados, que em geral trabalham em condições mais precárias; inclusive em termos de saúde e segurança do trabalho. "A terceirização pode ser lida como sinônimo de precarização, pois, como é sabido, a qualidade dos postos de trabalho está diretamente associada ao tipo de empresa: os melhores tendem a estar concentrados nas grandes empresas (locus por excelência do emprego "fordista"), sobretudo no caso brasileiro, onde esse padrão esteve sempre limitado às multinacionais, às estatais e a algumas empresas nacionais" (BORGES; DRUCKER, 2002, p.133)

A chamada "flexibilização" do trabalho representa, na maioria das vezes, um eufemismo para acobertar a precarização das condições de trabalho e a supressão de direitos trabalhistas. A reestruturação das leis trabalhistas e as intensas mudanças no mercado de (c) (1) @ REAd | Porto Alegre - Vol. 26 - N. ${ }^{\circ} 2$ - Maio / Agosto 2020 - p. 330-351. 
trabalho promoveram fenômenos sociais como o desemprego, a alta rotatividade, contratação de trabalhadores temporários, em tempo parcial e que podem ser demitidos com menos custos. Dessa forma, amparados em lei, observa-se o aumento da terceirização, da subcontratação, da informalidade, da precarização e das novas representações do trabalho escravo. A terceirização tem se transformado em um recurso de dissimulação, um instrumento utilizado pelas empresas para lidarem com a sazonalidade e volatilidade do mercado e, assim, aumentarem a lucratividade através da diminuição de custos com força de trabalho (HARVEY, 2007).

Historicamente, desde 1995 quando o Brasil reconheceu internacionalmente a existência de trabalho escravo em seu território e começou a implementar ações de fiscalização e combate, os casos recorrentes estão localizados principalmente no agronegócio, na zona rural do país, seguida da construção civil, com a contratação de trabalhadores nacionais, em sua maioria nordestinos que trabalham e residem em condições precárias nos próprios canteiros de obra, e mais recentemente, na cadeia produtiva da indústria têxtil, representado por oficinas de costura clandestinas que utilizam a mão de obra de imigrantes latino-americanos, normalmente o abuso recai sobre o imigrante em situação irregular, vítima da coação, do medo e da falta de oportunidades, localizadas em sua maioria na cidade de São Paulo (PEREIRA, 2008).

O extinto Ministério do Trabalho, agora incorporado ao Ministério da Economia, divulgou a quinta edição do cadastro de empregadores que tenham submetido trabalhadores a condições análogas à de escravo, também chamada de "lista suja" sobre o trabalho escravo contemporâneo no país. A lista mais recente, publicada em 2019, inclui quarenta e oito novas organizações em relação à última lista divulgada, no ano de 2016. Entre os anos 2016 e 2019 não foram divulgadas listas. A maioria das organizações autuadas e mencionadas nesta lista localiza-se nos setores de agronegócio e construção civil, mas trouxe novamente organizações ligadas ao varejo têxtil, como marcas de luxo da moda fast fashion que contrataram costureiros imigrantes indocumentados em sua cadeia produtiva, prática recorrente do setor.

No entanto, nessa edição da lista aparecem duas ocorrências consideradas inéditas, representadas por duas reconhecidas organizações que produzem e comercializam café, ambas ostentam selos de boas práticas e fornecem grãos para duas redes de cafeterias internacionais reconhecidas mundialmente. A respeito desse caso, o relatório de autuação dos auditores do trabalho apresenta descrição de trabalhadores cumprindo jornadas exaustivas de $6 \mathrm{~h}$ às $23 \mathrm{~h}$, morando em condições de higiene consideradas degradantes nos alojamentos. Outro caso que (c) $(1) \Theta$ REAd | Porto Alegre - Vol. 26 - N. ${ }^{\text {o }} 2$ - Maio / Agosto 2020 - p. 330-351. 
desperta a atenção foi a presença de duas organizações que fornecem serviços de babás e empregadas domésticas em São Paulo, estas foram autuadas por exploração de mulheres imigrantes filipinas (MINISTÉRIO DA ECONOMIA [ME], 2019).

Essa lista, que traz a relação dos casos nos quais os empregadores tiveram direito à defesa administrativa em primeira e segunda instâncias, foi mantida sob sigilo durante vários anos, o que justifica sua emissão em alguns anos, e começou a ser divulgada por força da Lei 12.527 - Lei de Acesso à Informação (LAI), que sanciona o acesso a informações públicas. A LAI foi sancionada em 18 de novembro de 2011, mas só entrou em vigor em 16 de maio de 2012, como previsto em seu texto (BRASIL, 2016). Porém, em meio a disputas judiciais, ora o Supremo Tribunal Federal (STF) proíbe, ora autoriza a liberação dessas informações, o que parece ser um contrassenso, uma vez que a sociedade brasileira tem o direito de conhecer as práticas ilícitas dessas organizações ao mesmo tempo em que ser transparente é um valor reconhecido pelo mercado (MINISTÉRIO DA ECONOMIA [ME], 2019).

\section{3 À GUISA DE UMA CONCLUSÃO}

O trabalho em condição análoga a de escravo, ou ainda, o trabalho análogo ao escravo, recebe diversas denominações e é motivo de controvérsias. É um tema recorrente na mídia nacional e estrangeira que provoca discussões na sociedade civil, governo e academia, e constitui-se como um enorme desafio aos operadores do direito, especialmente a partir de 2003, quando o texto do art. 149 do Código Penal Brasileiro se torna mais preciso sobre o que tipifica o crime. É importante compreender a mudança que ocorreu nesse artigo no ano de 2003, por meio da Lei 10.803/2003, pois representa um avanço à discussão, ao ampliar as condutas a serem punidas, indo para além da condição de trabalho forçado e a 'privação da liberdade' do trabalhador, que vigorava no texto anterior, datado do ano de 1940, passando a punir também o trabalho degradante e em condições abusivas que ferem a dignidade humana. Como herança histórica semântica, no texto anterior, o léxico "liberdade" centralizava a condição do crime, o que pressupõe uma herança dos significados herdados da escravidão colonial. Em sua versão atual, já não é mais o principal direito a ser cerceado, mas, a de ferir a condição da dignidade humana, quando lhe é negado uma condição de trabalho decente (BRITO FILHO, 2006; 2010).

Dessa forma, tanto no nível semântico como no nível jurídico, na interpretação da lei, o trabalho escravo contemporâneo está associado a conjunção de pelo menos duas práticas (c) (1) 9 REAd | Porto Alegre - Vol. 26 - N. ${ }^{\circ} 2$ - Maio / Agosto 2020 - p. 330-351. 
recorrentes: "o trabalho degradante" e a "privação de liberdade". Associado a essa condição, e na tentativa de se distanciar de seu sentido histórico, recorre-se a semântica do eufemismo para abrandar o peso que o nome carrega com o emprego de adjetivos que acompanham o substantivo escravidão, tais como: "branca", "semi", "contemporânea", "neoescravidão", "moderna", "por dívida", "análoga". Além disso, há ainda a substituição do termo por expressões como "trabalho forçado", "jornada exaustiva", "condição degradante" e impor "restrições" aos trabalhadores, previstos na portaria MTB 1.293, de 28 de dezembro de 2017, nos artigos 1 e 2, que reconhece "a condição análoga à de escravo".

Não se trata apenas de estratégias linguísticas, pois esses recursos semânticos acabam influenciando na tipificação do crime e seu julgamento, afinal, a definição do trabalho escravo na contemporaneidade não é apenas fruto de uma discussão a partir de categorias abstratas da linguística. "Ela é fruto de motivações sociais e políticas, conseguindo aos poucos se impor pelas pressões, principalmente de órgãos de Direitos Humano", que definem o trabalho escravo na atualidade como "[...] aquele que se realiza mediante a redução do trabalhador a simples objeto de lucro do empregador", é aquele no qual o trabalhador "é subjugado, humilhado e submetido a condições degradantes de trabalho e, em regra, embora não seja elemento essencial do tipo, sem o direito de rescindir o contrato ou de deixar o local de labor a qualquer tempo". (MIRAGLIA, 2008, p. 135). É quando se fere a dignidade humana, quando "o trabalhador é submetido à violência física e simbólica do particular, forja-se uma relação social que, com frequência, não leva em conta a humanidade do outro" (FIGUEIRA, 2004, p. 176).

Embora tenha se reconfigurado ao longo dos séculos, os principais atributos da escravidão permanecem os mesmos utilizados no passado - o controle exercido sobre o trabalhador, baseado no uso simbólico ou real da violência; a falta de remuneração justa, além da subsistência; a apropriação do trabalho e/ou de outras qualidades do escravo para ganho econômico. A escravidão "compartilha esses atributos, embora reconheça-se que possa existir exceções ocasionais, mas o atributo chave e central, o núcleo da escravidão é a condição do controle potencialmente violento de uma pessoa por outra" (BALES, 2006, p. 2).

Aproximando a discussão para os dias atuais, a escravidão contemporânea no Brasil configura-se a partir de uma herança do trabalho escravo, uma categoria extinta juridicamente, mas que subsiste socialmente, dissimulada em práticas de contratação e remuneração de trabalhadores que continuam na situação de assujeitamento, pois permanecem a condição de exploração e sujeição do trabalhador. No âmbito da discussão, as categorias (c) (1) (\$) 
históricas que representavam o trabalho escravo ganham novas configurações que se constituem como continuidades históricas. Talvez seja por isso que é tão difícil para quem está no comando (seja um latifundiário ou um empresário) admitir o trabalho escravo. O cerceamento da liberdade, condição nem sempre visível, pois não se utilizam mais as correntes e algemas, as ameaças físicas e psicológicas ou mesmo as grandes distâncias que separam a propriedade rural até a cidade mais próxima. As significativas mudanças sociais, com uma sociedade cada vez mais associada ao consumo e não mais ao trabalho; alterações evidentes na legislação trabalhista, como a "flexibilização" e "terceirização irrestrita" que cerceiam leis protetivas aos direitos conquistados pelo trabalhador; as contraditórias e históricas relações de desigualdade e distribuição de renda, as lutas de classe e a reprodução das desigualdades permanecem inalteradas na contemporaneidade. A desregulamentação e flexibilização das relações de trabalho, juntamente com a reestruturação produtiva e a intervenção mínima do Estado acabam favorecendo ao mercado e criando um ambiente favorável à sua atuação, regulação e legitimação social.

As intervenções do Estado na busca pela igualdade não são bem-vindas nessa lógica mercantil e em seu lugar, a desigualdade e a livre concorrência assumem a responsabilidade pelo desenvolvimento social. A crítica neoliberal ao Estado é centrada em combater quaisquer ações que promovam a desmercantilização, a solidariedade e o coletivismo, além do caráter universal do direito humano. A escravidão resistiu e se reconfigurou no tempo e no espaço, ganhou novos formatos e conjunturas, explora nacionais e imigrantes, localiza-se em lugares sombrios e clandestinos, urbanos ou rurais, mas sobretudo está presente nas relações mercantis de organizações globais que acolhem essa prática de maneira primária, seja em fornecedores ou na extensão de sua cadeia produtiva.

A escravidão contemporânea não possui uma única expressão, mas assume as versões das várias organizações que dissimulam essa prática recorrente, seja apoiando-se na flexibilização das leis trabalhistas, na terceirização e quarteirização de seus serviços, na brandura da impunidade, seja nas condições de um trabalho precário, com jornadas exaustivas, executado em ambientes insalubres. Tais práticas estão resguardadas em organizações legitimadas, que funcionam na legalidade e mantem relações mercantis globais.

Escravidão "branca", "semiescravidão", "trabalho análogo ao de escravo", "escravidão contemporânea", em que se assemelham e em que se diferem? O termo "trabalho análogo ao de escravo" parece ser o mais reconhecido, pois não reconhece o trabalhador da condição de 
escravo, mas admite a condição de trabalho semelhante a de um escravo. Teríamos, dessa forma, uma relação de similitude que une o passado ao presente?

As analogias podem ser complicadas, pois, quando os sistemas são comparados, podese concluir, por exemplo, que a escravidão contemporânea possui traços ainda mais repugnantes, quando pensamos, por exemplo, que o trabalhador atual é descartável e facilmente substituído, enquanto o escravo antigo era considerado um bem de alto valor para o seu senhor, tanto que suas posses eram medidas, dentre outros, pela quantidade de escravos que ele possuía. Não se trata apenas de um detalhe semântico, mas do bom entendimento de uma categoria discursiva que tem o poder de interpretar a realidade social. De todo modo, sem uma conceituação precisa, torna-se difícil admitir que ainda existe a escravidão em solo brasileiro.

A própria disputa semântica acaba se tornando um recurso que reforça o silenciamento histórico, pois é mais fácil admitir o trabalho precário, por exemplo, na maioria dos casos, do que o trabalho escravo. A falta de uma conceituação produz, assim, desdobramentos históricos e sócio-políticos relevantes para a sociedade brasileira, que carrega um lastro de memórias que se confunde com a própria história do país, pois, para um gestor dos dias atuais, se ele não acorrenta seu trabalhador ao pé de uma mesa, ele não admite o trabalho escravo na organização. Enquanto as disputas semânticas ganham espaço na academia, a exploração de trabalhadores e as novas edições da chamada "lista suja" surpreendem a cada lançamento.

A herança escravista resiste e continua mediando as relações de trabalho do país. Nas condições atuais não prevalece mais a questão racial, há ressalvas e distinções, mas, de certa forma, se tornou ainda mais desafiante e complexa, sobretudo, pelas suas dissimulações e dificuldades de se fazer cumprir a lei. O trabalho escravo contemporâneo no Brasil está relacionado à herança cultural, a desigualdade e a impunidade. Passados mais de 120 anos após a assinatura da Lei Áurea, o país ainda mantém em sua memória marcas do passado que se refletem em práticas de exploração de mão-de-obra análoga à escrava. Dados oficiais do governo informam que entre 1995 e 2015, cerca de 50 mil pessoas foram libertas da escravidão no país. Esses dados demonstram uma grave violação aos direitos humanos para a comunidade nacional e internacional.

Em meio ao debate interdisciplinar que atravessa o tema, é possível iluminar a discussão a partir de uma perspectiva mais próxima ainda da Administração, que engloba os aspectos econômicos e culturais das relações sociais, legais e humanas das relações (c) (1) $(9$ 
trabalhistas dentro e fora do ambiente organizacional. Os aspectos morais e éticos das faces do novo capitalismo, o modo de produção e os espaços ocupados por organizações que atuam nos limites entre o formal, o informal e o ilegal. A escravidão contemporânea trocou a senzala pela organização, a evidência na questão racial pela situação de pobreza e vulnerabilidade e o contexto histórico colonial pelo neocapitalismo de intensas desigualdades sociais. Dessa forma, trabalhadores, brasileiros e estrangeiros, abandonam suas cidades e países e se deslocam em busca de promessas feitas por aliciadores, com o objetivo de garantirem sua sobrevivência. A situação de vulnerabilidade desses trabalhadores favorece a mitigação de direitos e princípios protetivos estabelecidos na legislação vigente do país. A escravidão contemporânea, que tem atualmente como seu lócus principal o perímetro urbano, adquiriu novas configurações e tem resistido às diversas atuações e políticas de enfrentamento por parte do Estado e de organismos nacionais e internacionais.

Não se trata de uma venda da força de trabalho como mercadoria, pois as pessoas escravizadas não são livres para vender sua própria força de trabalho como mercadoria, antes são exploradas e mantidos em condições de violência (BALES; ROBBINS, 2001). Os novos formatos desafiam e parecem paralisar os avanços e as transformações socioeconômicas e políticas em prol do trabalho digno, podemos observar isso, por exemplo, no fenômeno denominado de novo proletariado da era digital, ou ainda a uberização do trabalho (ANTUNES, 2018).

As reflexões possíveis a partir desse estudo apontam que, em detrimento das lutas travadas pela sua extinção até os dias atuais, pode-se afirmar que o trabalho escravo tem resistido e se reconfigurado no tempo e no espaço, e se constitui em um enorme desafio aos pesquisadores de estudos organizacionais. Pois o sistema de escravidão aparece e reaparece ao longo da história do trabalho, de maneira atemporal, assumindo novos contextos e formatos, da senzala à escravidão fabril, as oficinas de costura que integram a cadeia produtiva da indústria têxtil, negócios agropecuários, construção civil e outros setores da economia. Seja utilizando a mão de obra de nacionais ou imigrantes, o trabalho escravo é, sobretudo, fruto das ostensivas desigualdades sociais que devastam o mundo.

\section{REFERÊNCIAS}

ALMEIDA, A. A. de. Vidas em transe: trabalho escravo e direitos humanos no brasil contemporâneo (1994-2006). Olhares e Trilhas, v. 9, n. 9, p. 107-115, 2008.

(c) $\frac{(1)(9)}{a r} \operatorname{REAd} \mid$ Porto Alegre - Vol. 26 - N. ${ }^{\circ} 2$ - Maio / Agosto 2020 - p. 330-351. 
ANTUNES, R. O Privilégio da Servidão: o novo proletariado de serviços na era digital, Ed. Boitempo, 2018.

BALES, K. Disposal people: new slavery in global economy. Califórnia: Califórnia Press, 2004.

BALES, K. Testing a theory of modern slavery. Washington: Free the Slaves, 2006. Disponível em: $<$ https://www.freetheslaves.net/wp-content/uploads/2015/01/Testing-aTheory-of-Modern-Slavery.pdf $>$. Acesso em: 07/07/2020.

BALES, K.; DATTA, M. N. Slavery as social institution. International Encyclopedia of the Social \& Behavioral Sciences, v. 21, n. 3, p. 14146-14152, 2015.

BALES, K.; ROBBINS, T. No one shall be held in slavery or servitude: a critical analysis of International Slavery Agreements and Concepts of Slavery. Human Rights Review, v. 2, n. 2, p. 18-45, 2001.

BAPTISTA, R. M.; BANDEIRA, M. L.; SOUZA, M. T. S. de. A invisibilização do negro no trabalho escravo contemporâneo: evidências a partir das condições de vulnerabilidade social. Organizações e Sociedade, v. 25, n. 87, p.676-703, 2018.

BARRoS, A. M. de. Curso de direito do trabalho. São Paulo: LTr, 2012.

BIBLIOTECA NACIONAL DO RIO DE JANEIRO. Para uma história do negro no Brasil. Catálogo de Exposição. Rio de Janeiro: Biblioteca Nacional. Recuperado em 05 de abril, 2019, de http://objdigital.bn.br/acervo_digital/div_iconografia/icon1104317/icon1104317.pdf, 1988.

BIBLIOTECA NACIONAL DIGITAL DO BRASIL. (n.d.). Tráficos de escravos no Brasil. $\begin{array}{llllll}\text { Recuperado em } & 05 & \text { de } & \text { abril, } & 2019 & \text { de }\end{array}$ http://bndigital.bn.gov.br/projetos/escravos/introducao.html.

BORGES, A.; DRUCK, G. Terceirização: balanço de uma década. Caderno CRH, v. 15, n. 37, p. 111-139, 2002.

BRASIL. Decreto-lei no 2.848, de 7 de setembro de 1940. Código Penal, 1940. Disponível em: http://www.planalto.gov.br/ccivil_03/decreto-lei/del2848.htm. Acesso em: 04/02/2019.

BRASIL. República Federativa do Brasil. Ministério da Justiça e Cidadania. Sobre a Lei de Acesso à Informação (LAI), 2016. Recuperado a partir de http://www.justica.gov.br. Acesso em 06/04/2019.

BRASIL. República Federativa do Brasil. Ministério do Trabalho e Emprego. Lista da Transparência, 2019. Recuperado em 15 de maio de 2019 em http://trabalho.gov.br/trab_escravo/lista_suja.pdf.

BRASIL. Ministério do Trabalho e Previdência Social. Portaria MTB $\mathrm{n}^{\circ} 1.129$, de 13 de outubro de 2017, 2017. Dispõe sobre os conceitos de trabalho forçado, jornada exaustiva (c) (1) $\Theta$ REAd | Porto Alegre - Vol. 26 - N. ${ }^{\circ} 2$ - Maio / Agosto 2020 - p. 330-351. 
e condições análogas à de escravo para fins de concessão de seguro-desemprego ao trabalhador que vier a ser resgatado em fiscalização do Ministério do Trabalho, nos termos do art. $2^{\circ}$-C da Lei $n^{\circ} 7.998$, de 11 de janeiro de 1990; bem como altera dispositivos da Portaria Interministerial MTPS/MMIRDH no 4, de 11 de maio de 2016.

BRITO FILHO, J. C. M. de. Trabalho decente: análise jurídica da exploração do trabalho trabalho forçado e outras formas de trabalho indigno. São Paulo: LTr, 2010.

BRITO FILHO, J. C. M. de. Trabalho escravo: caracterização jurídica. São Paulo: LTr, 2014.

BRUSANTIN, B.; BARBOSA, V.; CAMPOS, E. André Rebouças, Joaquim Nabuco e a abolição: algumas correspondências. Anais do IV Colóquio de História da Universidade Católica de Pernambuco - UNICAP, Recife, PE, p. 45-60, 2010.

CASTRO, R. F. A terceirização no direito do trabalho. São Paulo: Malheiros, 2000.

CHAVEZ CORTEZ, J. Trabalho escravo no contrato de emprego e os direitos fundamentais. São Paulo: LTr, 2013.

COOKE, B. The denial of slavery in management studies. Journal of Management Studies, n. 40, p. 1895-1918, 2003.

COSTA, R. P. O caráter senhorial beneditino. Pernambuco, séculos XVIII E XIX. Revista Religare, v. 11, n. 2, p.317-342, 2014.

CRANE, A. Modern slavery as a management practice: exploring the conditions and capabilities for human exploitation. Academy of Management Review, New York, v. 38, n. 1, p. 53, 14, 2013.

DATTA, M. N.; BALES, K. Slavery in Europe: Part 1, estimating the dark figure. Human Rights Quarterly, v. 35, p. 817-829, 2013.

FERNANDES, F. A integração do negro na sociedade de classes. São Paulo: Ed. Dominus, 1965.

FERNANDES, M. F. L. Os republicanos e a abolição. Revista de Sociologia e Política, n. 27, p. 181-195, 2006.

FIGUEIRA, R. R. Por que o trabalho escravo? Estudos Avançados, v. 14, n. 38, p. 31-50, 2000.

FIGUEIRA, R. R. Pisando fora da própria sombra: a escravidão por dívida no Brasil contemporâneo. Rio de Janeiro: Civilização Brasileira, 2004.

FLORENTINO, M.; GOES, J. R. A paz nas Senzalas: famílias escravas e tráfico atlântico. Rio de Janeiro: Civilização Brasileira, 1997. 
GUARINELLO, N. L. Escravos sem senhores: escravidão, trabalho e poder no Mundo Romano. Revista Brasileira de História, v. 26, n. 52, p.227-246, 2006.

HARVEY, D. Condição pós-moderna. São Paulo: Edições Loyola, 2007

HAYEK, M.; NOVICEVIC, M. M.; HUMPHREYS, J. H.; JONES, N. Ending the denial of slavery in management history: Paternalistic leadership of Joseph Emory Davis, Journal of Management History, v. 16, n. 3, p. 367-379, 2010.

JUCÁ, J. A questão abolicionista na visão de André Rebouças. Cadernos de Estudos Sociais, v. 4, n. 2, p. 207-218, 1988.

LARA, S. H. Escravidão, cidadania e história do trabalho no Brasil. Projeto História, n. 16, p. 25-38, 1998.

LOVEJOY, P. A escravidão na África: uma história de suas transformações. Rio de Janeiro: Civilização Brasileira, 2002.

MARQUESE, R. de B. A dinâmica da escravidão no Brasil: resistência, tráfico negreiro e alforrias, séculos XVII a XIX. Novos Estudos - CEBRAP, n. 74, p.107-123, 2006.

MARQUESE, R. de B. O poder da escravidão: política e economia-mundo na construção da ordem escravista brasileira. São Paulo, 2012.

MARTINS, S. P. Direito do trabalho. São Paulo: Atlas, 2003.

MARTINS, S. P. A terceirização e o direito do trabalho. São Paulo: Atlas, 2001.

MASCARENHAS, A. O.; DIAS, S. L. G.; BAPTISTA, R. M. Elementos para Discussão da Escravidão Contemporânea como Prática de Gestão. Revista Administração Empresas, v.55, n.2, p.175-187, 2015.

MIRAGLIA, L. M. M. Trabalho escravo contemporâneo: conceituação à luz do princípio da dignidade da pessoa humana. São Paulo: LTr, 2015.

MORAES, E. de A. A campanha abolicionista (1879-1888). Brasília: Ed. da Universidade de Brasília - UNB, 1986.

NABUCO, J. O abolicionismo. Londres: Abraham Kingdon, 1883.

OIT. Organização Internacional do Trabalho. Trabalho escravo no Brasil do Século XXI. Brasília: OIT, 2006. Recuperado em 02 de fevereiro de 2019 em http://www.oitbrasil.org.br/sites/default/files/topic/forced_labour/pub/trabalho_escravo_no_br asil_do_\%20seculo_\%20xxi_315.pdf.

OIT. Organização Internacional do Trabalho. Convenção 105: abolição do trabalho forçado, 1957. Recuperado em 12 de abril, 2019 em http://www.oitbrasil.org.br/node/469. 
OIT. Organização Internacional do Trabalho. Mundo tem 40 milhões de pessoas na escravidão moderna e 152 milhões de crianças no trabalho infantil, 2017. $\begin{array}{llllll}\text { Recuperado em } & 15 & \text { de } & \text { maio, } & 2019 .\end{array}$ https://www.ilo.org/brasilia/noticias/WCMS 575482/lang--pt/index.htm.

ORLANDI, E. As formas do silêncio: no movimento dos sentidos. Campinas, SP: Editora da Unicamp, 2007.

PALO NETO, V. Conceito jurídico e combate ao trabalho escravo contemporâneo. São Paulo: LTr, 2008.

PATROCÍNIO, J. do. Semana Política por Prodhomme, pseudônimo. Rio de Janeiro: Gazeta da Tarde, 1882.

PEDROSO, E. da. Negação ao Reconhecimento da Escravidão Contemporânea. In: VELlOSO, G.; FAVA, M. N. (orgs.). Trabalho Escravo Contemporâneo: O Desafio de Superar a Negação (p. 13 - 59). São Paulo: LTr, 2006.

PEREIRA, L. F. A escravidão contemporânea e os princípios do Direito do Trabalho. Revista Âmbito Jurídico, v. 11, n. 59, 2008.

PINSKY, J. A escravidão no Brasil. São Paulo: Contexto, 2012.

QUEIROZ, C. A. R. Como Implantar a Terceirização. São Paulo: STS, 1999.

RAMOS, I. L. F. Slave labour: the José Pereira case and its relevance in presente Brazil. Cosmopolitan Law Journal, v. 2, n. 2-4, p. 88-102, 2016.

SILVA, M. R. O desafio de definir o trabalho análogo ao de escravo. Revista do Direito do Trabalho. Brasília: LTr, v. 35, n. 139, p. 202-230, 2009.

VILLELA, F. G. Manual de Direito do Trabalho. Rio de Janeiro: Elsevier, 2010. 